\title{
Intracerebral temperature in patients with hydrocephalus of varying aetiology
}

\author{
Yutaka Hirashima, Michiyasu Takaba, Shunro Endo, Nakamasa Hayashi, \\ Kazuhiko Yamashita, Akira Takaku
}

\begin{abstract}
Brain temperature was measured at various depths beneath the pial surface in patients with hydrocephalus of varying aetiology. Temperature increased gradually with depth in all patients, with the highest temperature found in the ventricle. The difference between intraventricular and rectal temperatures $(\Delta v-r)$ was greater in patients who underwent continuous ventricular drainage than in patients who underwent ventriculoperitoneal shunt (continuous ventricular drainage; $1.2(\mathrm{SD} \mathrm{0.40)})^{\circ} \mathrm{C}$, mean (SD), $\mathrm{n}=5$ $v$ ventriculoperitoneal shunt; 0.4 (SD $\left.0.45)^{\circ} \mathrm{C}, \mathrm{n}=16 ; \mathrm{p}<0.05\right)$. The difference between intracerebral and rectal temperatures $(\Delta b 2-r)$ was also greater in patients with continuous ventricular drainage than in patients with ventriculoperitoneal shunt (continuous ventricular drainage; $0.1(\mathrm{SD} 0.86)^{\circ} \mathrm{C}, \mathrm{n}=5 v$ ventriculoperitoneal shunt; $-0.7(0.86)^{\circ} \mathrm{C}$, $\mathrm{n}=16 ; \mathrm{p}<\mathrm{0.05}$ ). Among patients with normal pressure hydrocephalus, these differences were greater in the patients with better outcomes after shunt surgery than in the less improved group $(\Delta v-\mathbf{r} ; 0.7$ $(\mathrm{SD} \mathrm{0.27})^{\circ} \mathrm{C}, \mathrm{n}=7 \quad \boldsymbol{v} 0.1(\mathrm{SD} \mathrm{0.40})^{\circ} \mathrm{C}, \mathrm{n}=5$, $\mathrm{p}<0.01, \Delta \mathrm{b} 2-\mathrm{r} ;-0.2(\mathrm{SD} 0.61)^{\circ} \mathrm{C}, \mathrm{n}=7 v$ $\left.-1.4(0.90)^{\circ} \mathrm{C}, \mathrm{n}=5, \mathrm{p}<0.01\right)$.

(F Neurol Neurosurg Psychiatry 1998;64:792-794)
\end{abstract}

Keywords: brain temperature; hydrocephalus; shunt surgery

The temperature of the brain is known to be higher than the body core. ${ }^{1}$ Furthermore, temperature gradient within the brain has also been reported in animal and human studies. ${ }^{2-5}$ The relation between brain damage and a cerebral temperature gradient has been discussed. ${ }^{5}$ In the present study we measured brain temperature at various depths beneath the surface during ventricular drainage operations in patients with hydrocephalus due to various aetiologies. We also examined the relation between brain temperature and outcome after shunt operation in hydrocephalic patients, particularly in patients with normal pressure hydrocephalus.

\section{Methods}

PATIENTS

Intracerebral temperature was examined in 20 patients (nine men and 11 women; ages 40 to 82 years, mean 66.8 ), who were admitted to the Department of Neurosurgery, Toyama Medical and Pharmaceutical University between January and December 1993 with hydrocephalus of various aetiologies (table). Five patients were diagnosed as acute hydrocephalus by repeated brain CT which showed increased ventricular dilation in the short term. They had subarachnoid haemorrhage, casting intraventricular haemorrhage due to thalamic haemorrhage, or an intraventricular bleeding due to arteriovenous malformation, pineal region tumour, and cerebellopontine angle tumour. Continuous ventricular drainage was performed in these five patients. Another 15 patients had developed less acute hydrocephalus. They were eight patients with a history of $\mathrm{SAH}$; four patients with brain tumours including metastatic tumour, temporal lobe astrocytoma, cerbellopontine angle tumour, and pontine glioma; two patients with head injury; and one patient with cerebral infarction. Normal pressure hydrocephalus was diagnosed from the following criteria: (1) clinical symptoms consistent with normal pressure hydrocephalus (dementia, gait disturbance, urgency incontinence in any combination); (2) cranial CT compatible with the diagnosis; (3) absence of evidence of toxic or metabolic disturbances; (4) all of the following: (a) characteristic radioisotope, cisternographic pattern (ventricular reflux and block of convexity flow); (b) CT characteristics of positive prognostic value (enlarged ventricles and periventricular lucency); (c) improvement at CSF tap test. For 12 patients with normal pressure hydrocephalus and three patients with obstructive hydrocephalus, ventriculoperitoneal shunt was performed. For one patient with obstructive hydrocephalus due to intraventricular haemorrhage after thalamic haemorrhage, ventriculoperitoneal shunt was performed after continuous ventricular drainage. No patients had infection at the time of brain temperature recording. Symptoms of patients with normal pressure hydrocephalus were assessed three months after ventriculoperitoneal shunt. We evaluated improvement of dementia, gait 
Table 1 Summary of patient data

\begin{tabular}{|c|c|c|c|c|c|c|}
\hline Patient No & Age/sex & Diagnosis & Operation & $\operatorname{Tv}\left({ }^{\circ} \mathrm{C}\right)$ & $\Delta v-b 2\left({ }^{\circ} C\right)$ & $\Delta v-r\left({ }^{\circ} C\right)$ \\
\hline 1 & $75 / \mathrm{F}$ & $\mathrm{SAH}$ & CVD & 39.0 & 1.3 & 1.6 \\
\hline 2 & $82 / \mathrm{F}$ & AVM & CVD & 38.0 & 0.8 & 2.5 \\
\hline 3 & $77 / \mathrm{M}$ & BT & CVD & 38.3 & 1.4 & 0.9 \\
\hline 4 & $69 / \mathrm{F}$ & BT & CVD & 38.8 & 1.1 & 0.6 \\
\hline 5 & $79 / \mathrm{M}$ & $\mathrm{SAH}(\mathrm{NPH})$ & VPS & 36.7 & 1.0 & -0.1 \\
\hline 6 & $40 / \mathrm{M}$ & $\mathrm{SAH}(\mathrm{NPH})$ & VPS & 37.1 & 0.3 & 1.3 \\
\hline 7 & $50 / \mathrm{F}$ & SAH(NPH) & VPS & 37.3 & 0.7 & 0.7 \\
\hline 8 & $80 / \mathrm{F}$ & $\mathrm{SAH}(\mathrm{NPH})$ & VPS & 37.5 & 0.6 & 0.5 \\
\hline 9 & $59 / \mathrm{F}$ & SAH(NPH) & VPS & 37.1 & 1.8 & 0.6 \\
\hline 10 & $69 / \mathrm{F}$ & $\mathrm{SAH}(\mathrm{NPH})$ & VPS & 37.3 & 1.0 & 0.6 \\
\hline 11 & $73 / \mathrm{F}$ & SAH(NPH) & VPS & 36.6 & 2.7 & -0.1 \\
\hline 12 & $46 / \mathrm{M}$ & $\mathrm{SAH}(\mathrm{NPH})$ & VPS & 37.3 & 0.8 & 0.4 \\
\hline 13 & $69 / \mathrm{M}$ & $\mathrm{CI}(\mathrm{NPH})$ & VPS & 37.0 & 1.2 & -0.4 \\
\hline 14 & $64 / \mathrm{M}$ & $\mathrm{HT}(\mathrm{NPH})$ & VPS & 36.7 & 1.7 & 0.4 \\
\hline 15 & $76 / \mathrm{F}$ & $\mathrm{HT}(\mathrm{NPH})$ & VPS & 36.2 & 0.7 & 0.7 \\
\hline 16 & $76 / \mathrm{M}$ & $\mathrm{BT}(\mathrm{NPH})$ & VPS & 37.0 & 0.7 & 0.7 \\
\hline 17 & $52 / \mathrm{M}$ & $\mathrm{BT}$ & VPS & 36.6 & 1.3 & 0.6 \\
\hline 18 & $77 / \mathrm{F}$ & BT & VPS & 37.2 & 2.3 & 1.0 \\
\hline 19 & $54 / \mathrm{F}$ & BT & VPS & 36.8 & 0.6 & 0.3 \\
\hline \multirow[t]{3}{*}{20} & $69 / \mathrm{M}$ & Thalamic & CVD & 39.2 & 2.0 & 1.5 \\
\hline & & Haemorrhage & VPS & 37.1 & 1.0 & -0.3 \\
\hline & & & & $37.4(0.83)$ & $1.2(0.60)$ & $0.7(0.66)$ \\
\hline
\end{tabular}

$\mathrm{T} v=$ ventricular temperature; $\Delta \mathrm{v}-\mathrm{b} 2=$ the difference between intraventricular temperature and brain temperature at $2 \mathrm{~cm}$ depth from the brain surface; $\Delta v-r=$ the difference between intraventricular and rectal temperatures; $S A H=$ subarachnoid haemorrhage; $\mathrm{AVM}=$ arteriovenous malformation; $\mathrm{BT}=$ brain tumour; $\mathrm{CVD}=$ continuous ventricular drainage; $\mathrm{NPH}=$ normal pressure hydrocephalus; VPS=ventriculoperitoneal shunt; $\mathrm{CI}=$ cerebral infarction; $\mathrm{HT}=$ head truma.

disturbance, and urinary incontinence using an improvement score, with one point for improvement of each symptom (three points maximum total). These assessments were supported by objective examination such as measurement of gait speed, mental tests (mini mental state examination etc) and urodynamic study. We evaluated the relation between temperature indices and improvement score after ventriculoperitoneal shunt for normal pressure hydrocephalus. Patients were divided into two groups, one with improvement scores of 0 to 1 and another with scores of 2 to 3 . All patients gave informed consent for measurement of brain temperature.

TEMPERATURE MEASUREMENT

A copper-constantan thermocouple covered and isolated with a thin Teflon layer was introduced at the tip of Dandy's cannula. It was made to order (Biomedical Science, Kanazawa, Japan). The thermocouple was checked in a thermostatistically controlled water bath to verify accuracy over a temperature range between $30^{\circ} \mathrm{C}$ and $45^{\circ} \mathrm{C}$. Accuracy was $\pm 0.1^{\circ} \mathrm{C}$. Dandy's cannula was inserted through a frontal burr hole placed $3.0 \mathrm{~cm}$ lateral to the midline, immediately behind the coronal suture. Intracerebral temperatures were measured at intervals of $1 \mathrm{~cm}$ from the surface of the brain to the anterior horn of the lateral ventricle at the time of ventricular tapping for continuous ventricular drainage or ventriculoperitoneal shunt. At each measuring point, the cannula was fixed by free hand holding for one minute to obtain stable readings. A preliminary study showed that temperature readings were stabilised within 30 seconds when Dandy's cannula was moved from one water bath to another, from $28^{\circ} \mathrm{C}$ to $37^{\circ} \mathrm{C}$ or $45^{\circ} \mathrm{C}$ to $37^{\circ} \mathrm{C}$ (data not shown). Room temperature ranged from $21.5^{\circ} \mathrm{C}$ to $28.2^{\circ} \mathrm{C}$ (mean $25.6(\mathrm{SD} 1.69)^{\circ} \mathrm{C}, \mathrm{n}=21$ ). Dandy's cannula was soaked in water at various degrees in the room at $20^{\circ} \mathrm{C}$ and we measured the temperature at the surface and various depths below the surface. Although the temperature at the surface of the water was lower than that of the water, the temperature from $1 \mathrm{~cm}$ to $5 \mathrm{~cm}$ below the surface was constant. This suggests that the temperature at more than $1 \mathrm{~cm}$ below the brain surface is not under the influence of the room temperature. For rectal temperature measurement, commercially available thermocouples were used (Nihonkoden, Tokyo, Japan). The rectal thermocouple will measure the temperature 3 to $4 \mathrm{~cm}$ proximal to the anal spincter. Temperature indices were calculated from the measurements of ventricular temperature, brain temperature at $2 \mathrm{~cm}$ depth from the brain surface, and rectal temperature. Temperature indices included the difference between intraventricular and rectal temperature $(\Delta v-r)$, the difference between brain temperature at $2 \mathrm{~cm}$ depth from the brain surface and rectal temperature $(\Delta \mathrm{b} 2-\mathrm{r})$, and the difference between ventricular temperature and brain temperature at $2 \mathrm{~cm}$ depth from the brain surface $(\Delta v-b 2)$. Continuous ventricular drainage and ventriculoperitoneal shunt were performed using local anaesthesia and general anaesthesia using $66 \% \mathrm{~N}_{2} \mathrm{O}$ and $1 \%-2 \%$ isoflurane in oxygen respectively.

\section{STATISTICS}

Data are presented as mean (SD). The relation between brain depth and brain temperature was evaluated with Spearman's rank correlation. A paired $t$ test was used for statistical comparison of intraventricular and brain temperatures with rectal temperature. Wilcoxon's $U$ test was used for comparison of the differences of intraventricular and brain temperature from rectal temperature between patients with continuous ventricular drainage and ventriculoperitoneal shunt. The relation between improvement score and each index of brain temperature in patients with normal pressure hydrocephalus also was evaluated with Wilcoxon's $U$ test. A p value $<0.05$ was accepted as statistically significant. 


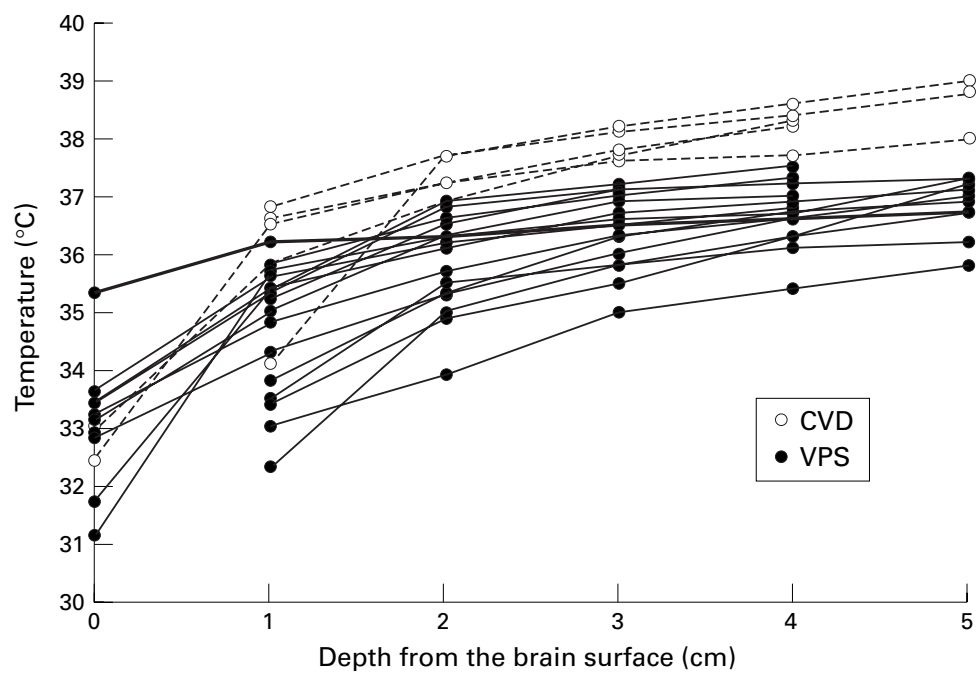

Temperature at various depths from the brain surface in 20 patients with hydrocephalus. Temperature measurement was performed on two occasions in a patient undergoing ventriculoperitoneal shunt after continuous ventricular drainage.

\section{Results}

Intracerebral temperature increased gradually with the depth of thermocouples in all patients (figure). There was a significant correlation between depth and brain temperature $(r=0.724, \mathrm{p}<0.0001$, figure). The ventricle was tapped 4 to $5 \mathrm{~cm}$ from the brain surface. The highest temperature was found in the anterior horn of the lateral ventricle (figure). Intraventricular temperature was higher than rectal temperature $\left(37.4(0.83)^{\circ} \mathrm{C} v 36.7(0.70)^{\circ} \mathrm{C}\right.$, $\mathrm{n}=21, \mathrm{p}<0.001)$ with differences of $-0.4^{\circ} \mathrm{C}$ to $1.6^{\circ} \mathrm{C}\left(0.6(0.55)^{\circ} \mathrm{C}\right)$, whereas brain temperature at $2 \mathrm{~cm}$ depth from the brain surface was lower than rectal temperature $\left(36.2(0.95)^{\circ} \mathrm{C} v\right.$ $\left.36.7(0.70)^{\circ} \mathrm{C}, \mathrm{n}=21, \mathrm{p}<0.025\right)$.

$\Delta v-r$ was significantly greater in patients with continuous ventricular drainage than in patients with ventriculoperitoneal shunt $(1.2$ $(0.40)^{\circ} \mathrm{C}, \mathrm{n}=5$ v $\left.0.4(0.45)^{\circ} \mathrm{C}, \mathrm{n}=16 ; \mathrm{p}<0.05\right)$. $\Delta \mathrm{b} 2-\mathrm{r}$ in patients with continuous ventricular drainage was also greater than in patients with ventriculoperitoneal shunt $\left(0.1(0.86)^{\circ} \mathrm{C}, \mathrm{n}=5\right.$ $\left.v-0.7(0.86)^{\circ} \mathrm{C}, \mathrm{n}=16 ; \mathrm{p}<0.05\right)$.

Although there was no difference in $\Delta v-b 2$ between two normal pressure hydrocephalus groups with improvement scores of 0 to 1 and those of 2 to 3 , indices such as $\Delta v-r$ and $\Delta \mathrm{b} 2-\mathrm{r}$ were greater in the patient group with scores 2 to 3 than in the less improved group $(\Delta v-r ; 0.7$ $(0.27)^{\circ} \mathrm{C}, \mathrm{n}=7$ v $0.1(0.40)^{\circ} \mathrm{C}, \mathrm{n}=5, \mathrm{p}<0.01$, and $\Delta \mathrm{b} 2-\mathrm{r} ;-0.2(0.61) \mathrm{C}, \mathrm{n}=7 v-1.4(0.90)^{\circ} \mathrm{C}$, $\mathrm{n}=5, \mathrm{p}<0.01)$.

\section{Discussion}

In experimental animals the temperature of the brain is known to be higher than that of arterial blood and the body core. ${ }^{1}$ In humans, brain temperature is higher than rectal temperature during monitoring when intracranial pressure is normal. ${ }^{6}$ The same finding has been made in the course of anaesthesia for intracranial surgery. ${ }^{7}$ The difference may reflect greater production of heat due to the higher metabolic activity of the brain. The difference of intraventricular and brain temperatures from rectal temperature in patients with continuous ventricular drainage were greater than those in patients with ventriculoperitoneal shunt. Continuous ventricular drainage and ventriculoperitoneal shunt were performed using local anaesthesia and general anaesthesia respectively. Therefore, lower brain temperature in patients with ventriculoperitoneal shunt may be attributed to decreased brain metabolic activity due to general anaesthesia. Additionally, higher brain temperature in acute hydrocephalic patients may be attributed to decreased cerebral blood flow due to increased intracranial pressure and decreased CSF flow due to stagnancy of CSF.

Furthermore, experimental studies have shown temperature gradients within the brain..$^{2-4}$ However, the topographic distribution of human brain temperature has not been reported except for an intracerebral temperature gradient found in two patients undergoing stereotactic thalamotomy. ${ }^{5}$ We confirmed this finding in all 20 patients with hydrocephalus. The brain surface temperature was lowest and that of the ventricle was highest. Brain temperature increased depending on brain depth. The temperature gradients for some patients in this study are greater compared with previous findings. ${ }^{2-6}$ Their brain CT showed remarkable bifrontal periventricular lucency. It is possible that greater gradients of temperature may be due to the trajectory of Dandy's cannula which crossed these subcortical regions.

For patients in the worst condition, the difference in temperature between the brain and the rectum gradually became smaller, probably reflecting lowered metabolic activity in the brain. ${ }^{6}$ In fact, Mellergård and Nordström have speculated that this gradient might afford a reliable basis for clinical judgment, ${ }^{6}$ although no correlation existed between the severity of patient status, which was reflected by conscious level, and a cerebral temperature gradient in further studies. ${ }^{5}$ In the present study, we estimated brain temperature with respect to outcome after shunt surgery for normal pressure hydrocephalus. The intraventricular and brain temperature during shunt surgery in patients with better outcomes were higher than in patients with worse outcomes. Higher temperature may reflect higher brain metabolic activity before shunt surgery. $\mathrm{Pa}-$ tients with higher cerebral metabolic activity, particularly in the frontal lobes, may have good postoperative recovery from symptoms such as dementia, gait disturbance, and urinary incontinence.

1 Hayward JN, Baker MA. A comparative study of the role of the cerebral arterial blood in the regulation of brain temperature in five mammals. Brain Res 1969;16:417-40.

2 Serota HM, Gerard RW. Localized temperature changes in the cat brain. $\mathcal{F}$ Neurophysiol 1938;1:115-24.

3 Deigado JMR, Hanai T. Intracerebral temperature in free-moving cats. Am F Physiol 1966;211:755-69.

4 Minamisawa $\mathrm{H}$, Mellergård $\mathrm{P}$, Smith ML, et al. Preservation of brain temperature during ischemia in rats. Stroke 1990; 21:758-64.

5 Mellergård $\mathrm{P}$. Intracerebral temperature in neurosurgical patients: intracerebral temperature gradients and relationpatients: intracerebral temperature gradients and relation-
ships to consciousness level. Surg Neurol 1995;43:91-5.

6 Mellergård P, Nordström CH. Intracerebral temperature in Mellergård P, Nordström CH. Intracerebral temperatu
neurosurgical patients. Neurosurgery 1991;28:709-13.

7 Meurosurgical patients. Neurosurgery 1991;28:709-13. Mellergård $\mathrm{P}$, Nordström $\mathrm{CH}$, Messeter $\mathrm{K}$. Human brain
temperature during anesthesia for intracranial operations. $\mathfrak{f}$ Neurosurg Anesth 1992;4:85-91. 